\title{
Energy Consumption, Carbon Dioxide Emissions and Economic Growth: Fresh Evidence From Panel Quantile Regressions
}

\author{
Buket Altinoz ${ }^{1}$, Nicholas Apergis ${ }^{2}$, Alper Aslan ${ }^{3}$ \\ ${ }^{1}$ Nisantasi University, Turkey, ${ }^{2}$ Economics and Finance, University of Derby, United Kingdom, ${ }^{3}$ Erciyes University, Turkey \\ Keywords: co2 emissions, panel quantile regression, economic growth, energy consumption \\ https://doi.org/10.46557/001c.17075
}

\section{Energy RESEARCH LETTERS}

Vol. 1, Issue 3, 2020

This paper analyzes the association between energy consumption, carbon dioxide emissions and economic growth. The results from panel quantile regressions for 57 countries and three different regions support deviations from sustainable growth in the full sample, as well as the European and Asian country samples. Similar results are obtained from Middle East and African countries, but the deviations begin earlier. In the Latin American findings, the estimates reveal that carbon emissions (at all levels) and energy consumption (at the medium and high levels) exert a negative impact on economic growth, indicating the inability of these countries to achieve sustainable economic growth.

\section{Introduction}

The literature identifies that energy and long-run economic growth are closely associated in countries around the globe (Baz et al., 2019; Rahman \& Velayutham, 2020; Salisu \& Ogbonna, 2019). However, sustainable growth is not independent of environmental problems. Therefore, it is imperative that the empirical research explicitly includes both energy consumption and environmental indicators (Gorus \& Aydin, 2019).

Admittedly, addressing economic growth only in the context of energy and the environment can have misleading results, while the complexity of the real world requires certain indicators that may be directly related to growth. The impact of foreign direct investment (FDI) on growth in relation to liberalization policies is also important (Anwar \& Nguyen, 2011; Omri \& Kahouli, 2014), given the profound role of FDI in new investments, up-to-date technologies, and managerial skills for the host countries (Pegkas, 2015). International trade, along with associated liberalization developments, seem to be also important for economic growth (Frankel \& Romeri, 1999; Musila \& Yiheyis, 2015). The literature emphasizes that economic growth also heavily depends on trade openness (Grossman \& Helpman, 1991; Spilimbergo, 2000). In contrast, as the share of the state in the economy is gradually shrinking, the role of government expenditures in economic growth is another important determinant, although its impact has generated mixed results (Kelly, 1997; Knoop, 1999).

The goal of this paper is to explore the nexus between energy consumption $(E C)$, carbon dioxide emissions $\left(\mathrm{CO}_{2}\right)$, gross capital formation $(G C F)$, labor force $(L)$, FDI, government expenditures (GE), trade openness (TO) and economic growth $(E G)$ across 57 countries, spanning the period 1990-2018. The study contributes in three ways. First, the energy-environment-growth nexus is considered along with $G C F, L, F D I$, and GE. Second, the analysis focuses on 57 countries from the European and Asian regions (22 countries), Latin American and Caribbean regions (15 countries), and Middle Eastern and African regions (20 countries). Finally, the analysis adopts a panel quantile regression model. The advantage of this method is that it allows not only heterogeneity across countries, but also provides different estimates, with respect to the mean, at the tails of the distribution.

\section{Literature review}

In the literature that uses panel-country studies, Saidi and Hammami (2015) reach the conclusion that for 58 countries (i.e. European and North Asian, Latin American and Caribbean, and Middle Eastern, North African and Sub-Saharan), there is a positive impact of $E G$ on $E C$, while $\mathrm{CO}_{2}$ emissions cause higher energy consumption at a global level. In the case of European and North Asian, and Latin American and Caribbean countries, higher levels of EG and $\mathrm{CO}_{2}$ emissions contribute to stronger EC. Similar country groups have also been employed by Acheampong (2018), who finds that $E C$ negatively affects $E G$ at the global level. Chen et al. (2016) show that energy use negatively impacts GDP. Gorus and Aydin (2019) consider the case of MENA countries. Their results signify the absence of any causal relationship between EG and environmental pollution, while Muhammad (2019), in the case of emerging and MENA countries, illustrates that $E G$ improves with $E C$ in both developed and emerging countries, while it declines in the case of MENA countries. He finds that $\mathrm{CO}_{2}$ emissions increase across all countries due to stronger $E C$.

\section{Model and Methodology}

The empirical analysis makes use of a basic production function accounting framework:

$$
G D P=f\left(E C, \mathrm{CO}_{2}, F D I, L, K, G E, T O\right)
$$

where $G D P$ denotes real GDP.

To the best of our knowledge, this paper is the first attempt to apply panel quantile regressions to explore the association between $\mathrm{CO}_{2}, E C$ and $E G$. A special advantage is these estimators are robust to outliers and skewed distributions. Moreover, allowing for unobserved heterogeneity, this method enables the exploration of differences in the growth rates among slow, moderate and fast-growing cases. In our sample, certain countries can grow faster than others; by contrast, OLS regressions provide estimates that 
Table 1: Panel quantile estimates (full sample)

\begin{tabular}{|c|c|c|c|c|c|}
\hline \multirow[b]{2}{*}{ Variables } & \multicolumn{5}{|c|}{ Quantiles } \\
\hline & $10 \%$ & $25 \%$ & $50 \%$ & $75 \%$ & $90 \%$ \\
\hline \multirow[t]{2}{*}{ C } & $0.327^{*}$ & $0.341^{*}$ & $0.319^{*}$ & $0.307^{*}$ & 0.286 \\
\hline & [0.08] & [0.07] & [0.09] & [0.10] & [0.13] \\
\hline \multirow[t]{2}{*}{$\mathrm{CO}_{2}$} & $0.042^{* *}$ & $0.049^{* *}$ & $0.045^{* *}$ & $-0.056^{* *}$ & $-0.061^{* * *}$ \\
\hline & [0.03] & {$[0.02]$} & {$[0.02]$} & [0.02] & [0.01] \\
\hline \multirow[t]{2}{*}{$E C$} & $0.058^{* * *}$ & $0.061^{* * *}$ & $0.065^{* * *}$ & $-0.074^{* * *}$ & $-0.078^{* * *}$ \\
\hline & [0.01] & {$[0.00]$} & {$[0.00]$} & {$[0.00]$} & {$[0.00]$} \\
\hline \multirow[t]{2}{*}{$L$} & $0.063^{* * *}$ & $0.058^{* * *}$ & $0.052^{* * *}$ & $0.045^{* * *}$ & $0.041^{* *}$ \\
\hline & {$[0.00]$} & {$[0.00]$} & {$[0.00]$} & [0.01] & [0.02] \\
\hline \multirow[t]{2}{*}{$F D I$} & $0.039^{* *}$ & $0.051^{* *}$ & $0.054^{* *}$ & $0.073^{* * *}$ & $0.079^{* * *}$ \\
\hline & {$[0.04]$} & {$[0.02]$} & {$[0.02]$} & {$[0.00]$} & {$[0.00]$} \\
\hline \multirow[t]{2}{*}{$G C F$} & $0.044^{* *}$ & $0.056^{* *}$ & $0.068^{* *}$ & $0.079^{* * *}$ & $0.084^{* * *}$ \\
\hline & [0.04] & [0.03] & {$[0.02]$} & [0.01] & {$[0.00]$} \\
\hline \multirow[t]{2}{*}{$G E$} & $0.067^{* * *}$ & $0.069^{* * *}$ & $0.061^{* * *}$ & $0.058^{* * *}$ & $0.059^{* * *}$ \\
\hline & {$[0.00]$} & {$[0.00]$} & {$[0.00]$} & {$[0.00]$} & {$[0.00]$} \\
\hline TO & $0.074^{* * *}$ & $0.077^{* * *}$ & $0.075^{* * *}$ & $0.079^{* * *}$ & $0.081^{* * *}$ \\
\hline [0.00] & {$[0.00]$} & {$[0.00]$} & {$[0.00]$} & [0.00] & [0.00] \\
\hline
\end{tabular}

The estimates are for the full sample per quantile, with low-growth-10-25\%; medium-growth-50\%; and high-growth-75-90\% representing the three quantile areas. The analysis employs the method proposed by Koenker (2004), based on the idea of penalized least squares interpretation of the classical random-effects estimators. Figures in brackets denote $p$-values. The asterisks ******* \& imply statistical significance at the $1 \%, 5 \%$ \& $10 \%$ levels, respectively.

represent the effect from an independent variable on the 'average country'. The analysis employs the method proposed by Koenker (2004), which uses the idea of penalized least squares interpretation of the classical random-effects estimator.

\section{Data}

The analysis uses annual data, spanning the period 1990 to 2018 for 57 countries belonging to three groups, i.e. the European and Asian region (22 countries), the Latin American region (15 countries), and the Middle Eastern, North African, and the Sub-Saharan region (20 countries). Data on real GDP (constant 2010 US dollars), $\mathrm{CO}_{2}$ emissions (metric tons per capita), $E C$ (in $\mathrm{kg}$ of oil equivalent per capita), FDI net inflows as percentage of GDP, GCF (in constant 2010 US dollars), $T O$ (the percentage of the sum of imports and exports to $G D P$ ), $G E$ as percentage of $G D P$, and $L$ measures (total workers) are obtained from the World Development Indicators database. All data are in logarithm form except those already in percentage terms.

\section{Empirical analysis}

Table 1 reports the estimates for the full sample per quantile (i.e., low-growth-10-25\%; medium-growth-50\%; and high-growth-75-90\%). Focusing on EC, the results show that $E G$ is heavily dependent on $E C$ across all growth quantiles. The coefficient appears positive and statistically significant only up to medium-growth levels, where then turns out to be negative. Similarly, in terms of $\mathrm{CO}_{2}$ emissions, the findings illustrate a positive effect on $E G$ up to medium-growth levels, while at high levels of $E G$ the coefficient turns out to be negative. In other words, at low growth levels, the growth process seems capable of sustaining environmental pollution. By contrast, at high levels, the evidence shows that countries do not invest in technologies that are environmentally friendly, implying that countries cannot achieve sustainable growth. Accordingly, although it is expected that strong $E G$ records can be high-energy efficient, compensating for the presence of increased emissions, does not hold in our full-country case.

The findings come in conflict with the literature that performs analysis with respect to the mean of the distribution, indicating the negative effect of $E C$ on $E G$ at high growth levels, thus, putting in jeopardy the validity of the growth hypothesis at these levels.

Table 2 reports the estimates per geographical region. $\mathrm{CO}_{2}$ and $\mathrm{EC}$ reveal a negative effect on $E G$ at high levels, implying that European countries cannot exert an efficient control over sustainable growth targets at high EG rates. In the Latin American countries, the estimates document that $\mathrm{CO}_{2}$ (at all levels) and EC (at the medium and high levels) exert a negative impact on $E G$, i.e. the inability of these countries to achieve sustainable EG. Finally, the results for the Middle East and African countries highlight that $E C$ cannot support $E G$ targets at high levels due to the presence of detrimental environmental effects.

\section{Conclusion}

This paper examines the impact of $E C$ and $\mathrm{CO}_{2}$ emissions on $E G$ for 57 countries from three different geographical regions over the period 1990-2018. The results with respect to the full sample and the European and Asian regions suggest that $E G$ is positively influenced by $\mathrm{CO}_{2}$ and $E C$ up to the medium growth levels, whereas it turned negative. The results imply that these economies witness deviations from 
Table 2: Panel quantile estimates (country groups)

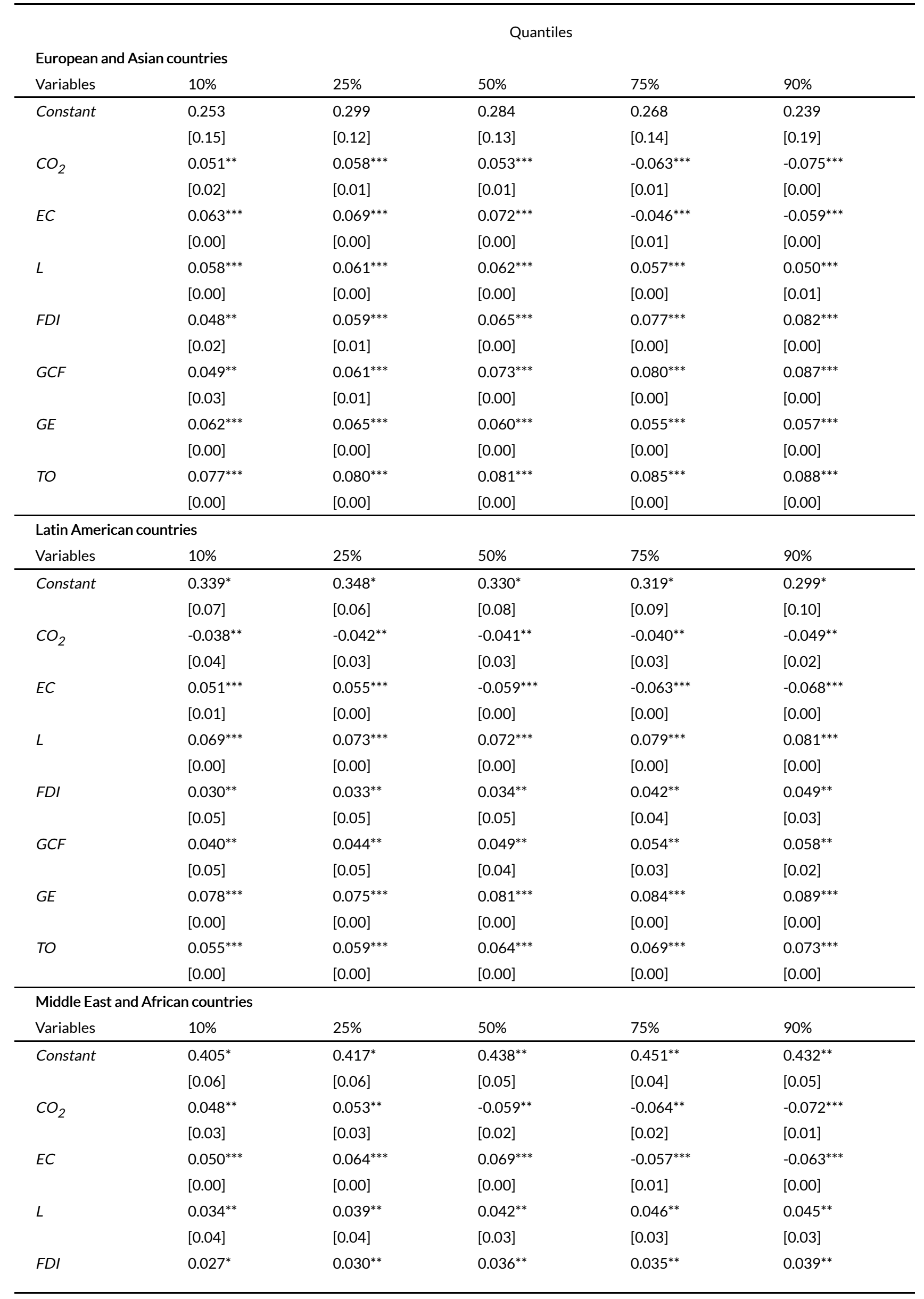




$\begin{array}{llllll} & {[0.06]} & {[0.05]} & {[0.05]} & {[0.05]} & {[0.04]} \\ G C F & 0.037^{* *} & 0.036^{* *} & 0.039^{* *} & 0.044^{* *} & 0.048^{* *} \\ & {[0.05]} & {[0.05]} & {[0.05]} & {[0.04]} & {[0.03]} \\ \text { GE } & 0.035^{* *} & 0.038^{* *} & 0.040^{* *} & 0.044^{* *} & 0.048^{* *} \\ & {[0.05]} & {[0.05]} & {[0.04]} & {[0.04]} & {[0.03]} \\ \text { TO } & 0.039^{* *} & 0.037^{* *} & 0.043^{* *} & 0.048^{* *} & 0.041^{* *} \\ & {[0.05]} & {[0.05]} & {[0.04]} & {[0.04]} & {[0.05]}\end{array}$

The estimates are for the full sample per quantile, with low-growth-10-25\%; medium-growth-50\%; and high-growth-75-90\% representing the three quantile areas. The analysis employs the method proposed by Koenker (2004), based on the idea of penalized least squares interpretation of the classical random-effects estimators. Figures in brackets denote p-values. The asterisks $* * * * * * \& *$ imply statistical significance at the $1 \%, 5 \% \& 10 \%$ levels, respectively. Figures in brackets denote p-values.

sustainability targets at high growth rates. The Middle East and African countries can achieve sustainability up to high levels of growth, but they are affected by $E C$ and $\mathrm{CO}_{2}$ after the medium growth levels. The evidence from the Latin American countries indicates a negative effect from $\mathrm{CO}_{2}$ emissions across all growth levels, i.e. they fail to achieve more sustainable growth.

The findings imply that European countries have come up with pioneering policies in terms of climate change and sustainability, but not at high growth levels. They need some long-run policies towards environmental investments. This is similar for the Asian, Middle East and African country groups. It is clear that more fundamental reforms are needed by the Latin American countries. They should encourage more environmentally friendly activities to mitigate carbon emissions.

\section{Acknowledgement}

The authors would like to thank the Editor and anonymous referees of Energy RESEARCH LETTERS.

\section{Appendix}

Country samples.

European and Asian (22 countries): Albania, Belgium, Bulgaria, Denmark, France, Germany, Greece, Hong Kong, Hungary, Iceland, Ireland, Italy, Japan, the Rep. of Korea, Luxembourg, the Netherlands, Norway, Portugal, Spain, Sweden, Switzerland, the UK.

Latin American (15 countries): Argentina, Bolivia, Brazil, Chile, Costa Rica, Ecuador, Guatemala, Honduras, Mexico, Nicaragua, Panama, Paraguay, Peru, Uruguay, Venezuela.

Middle East and African (20 countries): Algeria, Botswana, Cameroon, the Rep. of Congo, Cote d'Ivoire, Egypt, Ethiopia, Gabon, Ghana, Iran, Jordan, Kenya, Morocco, Mozambique, South Africa, Senegal, Sudan, Togo, Tunisia, Zambia.

This is an open-access article distributed under the terms of the Creative Commons Attribution 4.0 International License (CCBY-SA-4.0). View this license's legal deed at https://creativecommons.org/licenses/by-sa/4.0 and legal code at https://creativecommons.org/licenses/by-sa/4.0/legalcode for more information. 


\section{REFERENCES}

Acheampong, A. O. (2018). Economic growth, CO2 emissions and energy consumption: What causes what and where? Energy Economics, 74, 677-692. htt ps://doi.org/10.1016/j.eneco.2018.07.022

Anwar, S., \& Nguyen, L. P. (2011). Foreign direct investment and export spillovers: Evidence from Vietnam. International Business Review, 20(2), 177-193. https://doi.org/10.1016/j.ibusrev.2010.11.00 $\underline{2}$

Baz, K., Xu, D., Ampofo, G. M. K., Ali, I., Khan, I., Cheng, J., \& Ali, H. (2019). Energy consumption and economic growth nexus: New evidence from Pakistan using asymmetric analysis. Energy, 189, 1-16. http s://doi.org/10.1016/i.energy.2019.116254

Chen, P.-Y., Chen, S.-T., Hsu, C.-S., \& Chen, C.-C. (2016). Modeling the global relationship among economic growth, energy consumption and $\mathrm{CO} 2$ emissions. Renewable and Sustainable Energy Reviews, 65, 420-431. https://doi.org/10.1016/j.rser.2 $\underline{016.06 .074}$

Frankel, J. A., \& Romeri, D. (1999). Does trade cause growth? American Economic Review, 80(3), 379-399. https://doi.org/10.1257/aer.89.3.379

Gorus, M. S., \& Aydin, M. (2019). The relationship between energy consumption, economic growth, and CO2 emission in MENA countries: Causality analysis in the frequency domain. Energy, 168, 815-822. http s://doi.org/10.1016/j.energy.2018.11.139

Grossman, G. M., \& Helpman, E. (1991). Innovation and Growth in the Global Economy. MIT Press.

Kelly, T. (1997). Public expenditures and growth. Journal of Development Studies, 34(1), 60-84. http s://doi.org/10.1080/00220389708422503

Knoop, T. A. (1999). Growth, welfare, and the size of government. Journal of Economic Inquiry, 37(1), 103-119. https://doi.org/10.1111/i.1465-7295.1999.tb $\underline{01419 . x}$
Koenker, R. (2004). Quantile regression for longitudinal data. Journal of Multivariate Analysis, 91(1), 74-89. https://doi.org/10.1016/i.jmva.2004.0 $\underline{5.006}$

Muhammad, B. (2019). Energy consumption, CO2 emissions and economic growth in developed, emerging and Middle East and North Africa countries. Energy, 179, 232-245. https://doi.org/10.1016/j.energ y.2019.03.126

Musila, J. W., \& Yiheyis, Z. (2015). The impact of trade openness on growth: The case of Kenya. Journal of Policy Modelling, 37(2), 342-354. https://doi.org/1 0.1016/j.jpolmod.2014.12.001

Omri, A., \& Kahouli, B. (2014). The nexus among foreign direct investment, domestic capital and economic growth: Empirical evidence from the MENA region. Research in Economics, 68(3), 257-263. http s://doi.org/10.1016/j.rie.2013.11.001

Pegkas, P. (2015). The impact of FDI on economic growth in Eurozone countries. The Journal of Economic Asymmetries, 12(2), 124-132. https://doi.o $\mathrm{rg} / 10.1016 /$ j.jeca.2015.05.001

Rahman, M. M., \& Velayutham, E. (2020). Renewable and non-renewable energy consumption-economic growth nexus: New evidence from South Asia. Renewable Energy, 147, 399-408. https://doi.org/10.1 016/i.renene.2019.09.007

Saidi, K., \& Hammami, S. (2015). The impact of CO2 emissions and economic growth on energy consumption in 58 countries. Energy Reports, 1, 62-70. https://doi.org/10.1016/j.egyr.2015.01.003

Salisu, A. A., \& Ogbonna, A. E. (2019). Another look at the energy-growth nexus: New insight from MIDAS regression. Energy, 174, 69-84. https://doi.org/10.101 6/i.energy.2019.02.138

Spilimbergo, A. (2000). Growth and trade: The north can lose. Journal of Economic Growth, 5, 131-146. 